\title{
Selection for life-history traits to maximize population growth in an invasive marine species
}

Jaspers, Cornelia; Marty, Lise; Kiørboe, Thomas

Published in:

Global Change Biology

Link to article, DOI:

$10.1111 / \mathrm{gcb} .13955$

Publication date:

2018

Document Version

Peer reviewed version

Link back to DTU Orbit

Citation (APA):

Jaspers, C., Marty, L., \& Kiørboe, T. (2018). Selection for life-history traits to maximize population growth in an invasive marine species. Global Change Biology, 24(3), 1164-1174. https://doi.org/10.1111/gcb.13955

\section{General rights}

Copyright and moral rights for the publications made accessible in the public portal are retained by the authors and/or other copyright owners and it is a condition of accessing publications that users recognise and abide by the legal requirements associated with these rights.

- Users may download and print one copy of any publication from the public portal for the purpose of private study or research.

- You may not further distribute the material or use it for any profit-making activity or commercial gain

- You may freely distribute the URL identifying the publication in the public portal

If you believe that this document breaches copyright please contact us providing details, and we will remove access to the work immediately and investigate your claim 
Selection for life-history traits to maximize population growth in an invasive marine species

Running head: Life-history traits and invasion success

Cornelia Jaspers $^{1,2^{*}}$, Lise Marty ${ }^{1}$, Thomas Kiørboe ${ }^{1}$

${ }^{1}$ Centre for Ocean Life, DTU Aqua, Technical University of Denmark, Kemitorvet 202, 2800

Kgs. Lyngby, Denmark (CJ: coja@aqua.dtu.dk, LM: lise.marty@iplesp.upmc.fr, TK:

tk@aqua.dtu.dk)

${ }^{2}$ Evolutionary Ecology of Marine Fishes, Helmholtz Centre for Ocean Research Kiel, GEOMAR, Düsternbrooker Weg 20, 24105 Kiel, Germany (CJ: cjaspers@geomar.de)

*Corresponding author: GEOMAR, Helmholtz Centre for Ocean Research Kiel, Department: Evolutionary Ecology of Marine Fishes, Düsternbrooker Weg 20, 24105 Kiel, Germany, phone +49-431-600-4560, fax +49-431-600-4553, email coja@aqua.dtu.dk

Key words: Comb jelly, invasion ecology, evolutionary biology, Mnemiopsis leidyi, reproduction and population growth, evolution of life-history traits, jellyfish, global change

Type of paper: Primary research article 


\section{ABSTRACT}

Species establishing outside their natural range, negatively impacting local ecosystems, are of increasing global concern. They often display life-history features characteristic for $r$-selected populations with fast growth and high reproduction rates to achieve positive population growth rates $(r)$ in invaded habitats. Here, we demonstrate substantially earlier maturation at a 2 orders of magnitude lower body mass at first reproduction in invasive compared to native populations of the comb jelly Mnemiopsis leidyi. Empirical results are corroborated by a theoretical model for competing life-history traits that predicts maturation at the smallest possible size to optimize $r$, while individual life-time reproductive success $\left(\mathrm{R}_{0}\right)$, optimized in native populations, is near constant over a large range of intermediate maturation sizes. We suggest that high variability in reproductive tactics in native populations is an underappreciated determinant of invasiveness, acting as substrate upon which selection can act during the invasion process. 


\section{INTRODUCTION}

Biological invasions can have large ecological and economic impacts (Butchart et al., 2010; Walsh et al., 2016), especially in aquatic systems (Gallardo et al., 2016) and species translocations are steadily increasing worldwide (Butchart et al., 2010; Seebens et al., 2017). Of the non-indigenous species that are moved around the world, only a minute fraction become invasive and form self-sustained populations (Williamson \& Fitter, 1996; Mack et al., 2000). A long standing issue in ecology has been to characterize potent invasive species (Baker, 1974; Tingley et al., 2014) through traits that promote invasion success (Pysek \& Richardson, 2007; McKnight et al., 2017). There are examples from diverse organism groups showing that invasive and native populations differ in life-history traits (MacInnis \& Corkum, 2000; Fox et al., 2007; L'avrincikova \& Kovac, 2007), either because the invasion process filters individuals with certain traits, or because invaders evolve or are selected subsequent to invasion (Davis, 2005; Gutowsky \& Fox, 2012; Laugier et al., 2013; Fox \& Copp, 2014; Sargent \& Lodge, 2014). While certain traits make some species successful in colonizing new areas, there may also be differences within a species that make some individuals or subpopulations more successful than others (Lee \& Gelembiuk, 2008). Although a large body of literature has attempted to identify differences between native and invasive populations, the generality of such investigations is still inconclusive (Parker et al., 2013) and strongly context and invasion stage dependent (Van Kleunen et al., 2015; Chuang \& Peterson, 2016). For some plants, amphibians, and fresh water fish it has been shown that invasive sub-populations at the expansion front show opportunistic traits related to increased dispersal or reproduction rates compared to the core populations (Phillips et al., 2010; Gutowsky \& Fox, 2012; Lindström et al., 2013; Huang et al., 2015). However, other investigations using the same set of species did not observe such differences (Parker et al., 2013; Chuang \& Peterson, 2016). Specifically, in an analysis considering trait differences in 53 species, half of the species 
showed increased reproductive performance in invaded ranges. However, the difference was only observed in plants, while none of the investigated animals showed significant differences in reproductive traits (Parker et al., 2013). This lead Parker et al. (2013) to conclude, that although invaders may on average perform better, e.g., in terms of reproductive output, size, and abundances, this difference is largely driven by a few species displaying pronounced distinctions between the native and invasive range. Therefore, it remains an open question whether and how traits of invasive species differ between native and non-native areas (Ordonez, 2014).

From a general life-history perspective, one would expect that successful invasive populations should be selected for 'opportunistic' traits or be 'r-selected', while native populations in steady state would be more 'K-selected' (MacArthur \& Wilson, 1967; McMahon, 2002). More specifically, in a native population in ecological and evolutionary equilibrium, per capita population growth rate, $r$, and lifetime reproductive success, $R_{0}$, are two equivalent fitness measures, having a maximum (of 0 and 1, respectively) at the current optimal trait value. Invasive populations, in contrast, result from the colonization of a new habitat by a group of individuals with a positive population growth rate not yet at steady state, so that $r>0$ and $R_{0}>1$. In the latter scenario, it is hypothesized that strategies increasing the population growth rate will dominate the population. Thus, evolutionary processes including selection are expected to optimize the per capita population growth rate, $r$.

The marine holoplanktonic comb jelly Mnemiopsis leidyi, native to the east coast of America, is an example of a successful invasive species (Costello et al., 2012) with large ecosystem implications in northern and southern Europe (Kideys, 2002; Riisgård et al., 2007) and listed among the 100 worst invasive alien species worldwide (Lowe et al., 2000). It shares many characteristics of a successful invasive species due to high growth rates (Stanlaw et al., 1981) and its large reproductive potential (Jaspers et al., 2015a). Furthermore, M. leidyi is a 
simultaneous hermaphrodite and able to self-fertilize (Jaspers et al., 2015b). Producing viable offspring via self-fertilization allows this species to offset Allee effects, which otherwise may limit species during early colonization (Tobin et al., 2011). To our knowledge, marine holoplanktonic organisms with the ability to self-fertilize have not been considered in the context of life-history evolution in invasive species so far. As invasive species, they constitute an extreme case because dispersal is driven by prevailing ocean currents, and connectivity between regions in the marine realm is on average 1-2 orders of magnitude larger in comparison to terrestrial systems (Kinlan \& Gaines, 2003). Therefore, it may take longer before density-dependent processes become significant. We hypothesize that during the invasion of the comb jelly M. leidyi into western Eurasian waters, opportunistic life-history traits have been positively selected for. We compare life-history traits of several native and invaded populations of $M$. leidyi and apply life-history modelling to interpret the observations. In western Eurasian waters, two distinctly different invasion events can be separated. M. leidyi first occurred in the Black Sea during the early 1980's. A quarter of a century later, animals were also recorded in Northern Europe (Costello et al., 2012). Molecular analyses demonstrate that the invasive population present in the North originates from the north-east coast of the United States of America, whereas animals present in southwestern Eurasia originate from the Gulf of Mexico region (Reusch et al., 2010). This enables us to compare populations with different invasion histories to address the hypotheses (i) that life-history traits differ between native and invasive populations and (ii) that those traits are associated with maximizing $R_{0}$ and $r$ in native and invasive populations, respectively.

\section{MATERIALS AND METHODS}

Life-history model. We developed a life-history model for $M$. leidyi and optimized the per capita population growth rate $(r)$ and lifetime reproductive success $\left(R_{0}\right)$ to represent invasive 
and native populations, respectively. To examine how size at maturation is expected to change between native and invasive $M$. leidyi populations, we consider a size-structured population growing at a constant rate and explicitly describe the trade-off between somatic growth and reproduction at the individual level (Day \& Taylor, 1997). We numerically calculate individual per capita population growth rate $(r)$ and lifetime reproductive success $\left(R_{0}\right)$ for different sizes at maturation and compare the shape and maxima of the two fitness measures.

An individual's net energy acquisition rate, i.e., the surplus of energy after accounting for maintenance, scales with its weight $m$ as $h m^{n}$, where $h$ measures weight-specific acquisition rate and $n$ its scaling exponent. Somatic growth $g(m)$ and fecundity $b(m)$ compete for this surplus energy according to:

$$
g(m)=\frac{\partial m}{\partial a}=\left(1-\psi\left(m, m^{*}\right)\right) h m^{n}
$$

and

$$
b(m)=\frac{\psi\left(m, m^{*}\right) h m^{n}}{m_{0}}
$$

where $a$ denotes age, $b$ fecundity rate (eggs ind. $\left.{ }^{-1} \mathrm{~d}^{-1}\right), m_{0}$ the weight of an egg, and $m^{*}$ maturation size. $\psi\left(m, m^{*}\right)$ is the proportion of surplus energy devoted to reproduction, with $1-\psi\left(m, m^{*}\right)$ allocated to somatic growth. It is described by a sigmoidal function varying smoothly from 0 to 1 around the size at maturation:

$$
\psi\left(m, m^{*}\right)=\frac{1}{1+\left(m / m^{*}\right)^{\theta}}
$$

where $\theta$ is a shape parameter that describes the steepness of the transition from growth to reproduction. Mortality $\mu(m)$ consists of a constant term, $\mu_{0}$, unrelated to size, and a sizedependent predation mortality, $\mu_{1}$, scaling with body mass to power $n$ (Andersen $\&$ Beyer, 2006): 


$$
\mu(m)=\mu_{0}+\mu_{1} m^{n-1},
$$

with the same parameter $n(<1)$ as in equation 1 .

To describe the population dynamics, we use a size-structured population model. The density $N(t, m)$ of individuals of size $m$ at time $t$ is given by:

$$
\frac{\partial N(t, m)}{\partial t}=-\frac{\partial N(t, m) g(m)}{\partial m}-\mu(m) N(t, m)
$$

with a boundary condition of egg size giving the number of offspring produced in the population:

$$
g\left(m_{0}\right) N\left(t, m_{0}\right)=\int_{\mathrm{m}_{0}}^{\mathrm{m}_{\infty}} b(m) N(\mathrm{t}, m) \mathrm{d} m .
$$

When the population has reached a stable-size distribution, we expect it to grow exponentially at a constant rate $r$ :

$$
\frac{\partial N(t, m)}{\partial t}=r N(t, m)
$$

where $r$ is the per capita population growth rate.

Using equations (5) and (7) and solving the resulting ordinary differential equation gives the population density:

$$
N(t, m)=\frac{g\left(m_{0}\right) N\left(t, m_{0}\right)}{g(m)} \exp \left(-\int_{m_{0}}^{m} \frac{r+\mu(x)}{g(x)} \mathrm{d} x\right) .
$$

The characteristic equation is obtained by inserting $N(t, m)$ given by equation (8) into equation (6):

$$
1=\int_{m_{0}}^{m_{\infty}} \frac{b(m)}{g(m)} \exp \left(-\int_{m_{0}}^{m} \frac{r+\mu(x)}{g(x)} \mathrm{d} x\right) \mathrm{d} m .
$$

The root of the characteristic equation (9) is referred to as the dominant eigenvalue of the linear model (5) and gives the per capita population growth rate $r$.

Expected lifetime reproductive success ( $R_{0}$, dimensionless) is given by the right hand-side of equation (9) when $r$ is equal to 0 : 


$$
R_{0}=\int_{m_{0}}^{m_{\infty}} \frac{b(m)}{g(m)} \exp \left(-\int_{m_{0}}^{m} \frac{\mu(x)}{g(x)} d x\right) d m
$$

Fitness optimization. Model parameters are given in Table (1) and were estimated from laboratory experiments (see below) or from the literature as follows: Parameters $h, \theta$ and population mean maturation size $m^{*}$ in the life-history model were estimated by nonlinear least square fitting of equations (1) and (2) to the observed mass-dependent egg production and growth rates (Fig. S1). The allometric scaling of energy acquisition rate $(n)$ and mortality was taken from West et al. (1997), weight at hatch was set to be the same as egg weight $\left(m_{0}\right)$ and taken from Jaspers et al. (2015a), while the final individual size $\left(m_{\infty}\right)$ was assumed, based on observations and literature information of M. leidyi size distribution data in native and invaded habitats. This leads to a final individual length of $10 \mathrm{~cm}$ (oral-aboral), equivalent to $100 \mathrm{mgC}$ (Robinson \& Graham, 2014). Finally, the mortality parameters, $\mu_{0}$ and $\mu_{1}$, were estimated such that mortality at hatch was $0.15 \mathrm{~d}^{-1}$ (individual carbon weight: $0.3 \times 10^{-3} \mathrm{mgC}$ ) and declining to $0.1 \mathrm{~d}^{-1}(0.05 \mathrm{mgC})$ after 3 weeks of growth based on the magnitude and allometric scaling of the mortality rate of pelagic organisms (McGurk 1986).

To find the maturation size where $R_{0}$ and $r$ were the highest, we calculated these two fitness parameters for different mean maturation sizes $m^{*}$ using Mathematica 9.0, found the optima, and examined their sensitivity to change in parameters (Fig. 1, Table 2).

Size-dependent reproduction rates. Reproduction rates of Mnemiopsis leidyi as a function of age and size for both native and invasive populations and using both field and laboratory investigations were included in this analysis $(n=13$ studies/experiments see Table 3$)$. Data originate either from our own experiments or were extracted from the literature, leading to a total of 1010 individual size specific egg production rate data (see Table 3 for a full description). To allow for comparisson between different studies, we corrected all rates to a 
standard temperature of $19.5^{\circ} \mathrm{C}$, applying a $\mathrm{Q}_{10}$ of 2.8 (Hansen et al., 1997). We used oralaboral lengths as size standard and converted to mg body carbon using published conversion factors and length-mass regressions (Fig. S2; Kremer \& Nixon, 1976; Sullivan \& Gifford, 2004; Robinson \& Graham, 2014). For laboratory investigations, only experiments conducted at ad libitum or non-limiting food conditions (Jaspers et al., 2015b) were considered. For field investigations, statistical analyses included only rates measured at salinities $\geq 20$ to avoid confounding effects of low salinity on reproduction rates (Jaspers et al., 2011).

Laboratory experiments. To investigate growth and energy allocation in Mnemiopsis leidyi, a cohort of laboratory reared animals was followed for 40 days following hatch in spring 2010 at DTU Aqua in Charlottenlund, Denmark (Table 3, study 9). The cultured animals were originally collected in the southern Kattegat and a cohort was initiated from a controlled spawning event. On day 2 post hatch, 150 larvae were randomly picked and incubated in batches of 10 individuals in 15 0.32-L squared tissue culture bottles $\left(\right.$ Falcon $^{\circledR}$ ) that were mounted on a slowly $(0.9 \mathrm{rpm})$ rotating plankton wheel. $M$. leidyi were subsequently moved to increasingly larger incubation volumes and fed with increasingly larger size classes of the copepod Acartia tonsa at a target food concentration of $100 \mu \mathrm{g}$ A. tonsa $\mathrm{C} \mathrm{L}^{-1}$. Copepods originated from laboratory cultures fed with Rhodomonas salina and carbon was estimated from lengths using published regressions (Berggreen et al., 1988), accounted for shrinkage after Lugol preservation (Jaspers \& Carstensen, 2009). Prey concentrations were adjusted every day, while eggs and sizes were assessed every second day up to day 34 and daily thereafter. Eggs were concentrated by reverse filtration $(45 \mu \mathrm{m})$ and counted. Handling controls $(n=4)$ were performed with a total of 180 eggs, leading to an average egg loss 0.56\%. M. leidyi sizes (oral-aboral, $\mathrm{mm}$ ), were assessed by triplicate measurements of either images using ImageJ (Rasband, W.S., ImageJ) or live animals. Images were attained using a macro lens on a Nikon D70 SLR camera, while live animals were measured with a dissecting 
microscope and an ocular ruler or a caliper. We estimated growth rates $\left(\mu, \mathrm{d}^{-1}\right)$ from $(\mu=\ln$ $\left.\left(\mathrm{W}_{\mathrm{t}} / \mathrm{W}_{0}\right) / \mathrm{t}\right)$ where $\mathrm{W}_{0}$ and $\mathrm{W}_{\mathrm{t}}$ denote body carbon on day 0 and day $\mathrm{t}$, respectively. Specific egg production rates $\left(\mathrm{d}^{-1}\right)$ were calculated from egg counts and carbon contents of eggs (Jaspers et al., 2015a) and adults (see above). Energy allocation to reproduction was similarly assessed in a native cohort by Baker \& Reeve (1974); see Table 3, study 8 .

Common garden experiments with both invasive sub-populations from southern and northern Europe were conducted during spring 2015 (Table 3, study 11). These experiments were conducted to test for genetically underlain differences between sub-populations. To remove parental effects, wild larvae from the Caspian Sea and Baltic Sea were grown to adulthood at GEOMAR, Kiel and the F1 generation from these wild animals was used to run the common garden experiments. Even though experiments were first conducted with the F1 generation of wild caught parents entirely raised in the laboratory from larvae to adulthood, this may not have been enough to fully remove maternal effects (Dam, 2013). However, comparison of F1 and F3 generation egg production rates of southern invasive M. leidyi did not show significant differences in reproduction rates $(P=0.62)$. Rearing was conducted in 60-L glass aquaria with sterile filtered sea water (salinity $33,16^{\circ} \mathrm{C}$ ) and animals were fed $\mathrm{ad}$ libitum with a mixture of Acartia tonsa and Artemia salina. To initiate F1 generations, lobate M. leidyi were transferred into 60-L glass aquaria overnight and removed the next morning. The eggs were allowed to hatch and subsequently grow to adulthood. Randomly picked adults from the F1 generation were incubated in 7.5-L sterile filtered seawater for 24 hours and egg production measured following reverse filtration as above.

Similarly, during October 2015 southern invasive M. leidyi $(n=11)$ originating from a new spawn (F3 generation) of the permanent cultures kept at GEOMAR, Kiel, were investigated for egg production (Table 3, study 13). 
In situ experiments. We measured size-dependent egg production rates for invaded populations in Northern Europe $(n=97)$. Animals were caught in the Skagerrak $\left(58^{\circ} 15^{\prime} \mathrm{N}\right.$ $11^{\circ} 24^{\prime} \mathrm{E}$ ) during August/September 2010 (Table 3, study 5) and size-dependent egg production over 24 hours measured as outlined above.

Statistical analyses. Size-dependent egg production rates of northern and southern as well as invasive and native populations were analyzed using power regression analyses on raw data and a separate slopes model was used to test for differences between slopes and intercepts on $\log (\mathrm{x}+1)$ transformed data using co-variance analyses (GraphPad Prism V.4.0).

\section{RESULTS}

Following the laboratory cohort from hatch to adulthood (Table 3, study 9), we observed a change in growth rate during development along with a change in energy allocation between growth and reproduction (Fig. 1).

With parameters derived from the experiment we examined how $R_{0}$ and $r$ depend on mean maturation size $\left(m^{*}\right)$ : optimization of population growth rate $(r)$ implies that maturation size should be as small as possible, while optimizing for lifetime reproductive success $\left(R_{0}\right)$ leads to an optimum size for reproduction at $20 \mathrm{mg}$ body mass (Fig. 2, Table 1). However, the $R_{0}$ fitness curve is very flat, and lifetime reproductive success is thus nearly independent of maturation size over a large range of sizes (Fig. 2). The prediction that smallest possible maturation size optimizes population growth rate $(r)$ is independent of parameter choice, and the shape of the $R_{0}$ fitness curve is also robust to rather large variations in parameters (Table 2). But because the $R_{0}$ curve is flat, the precise maturation size optimizing $R_{0}$ varies between ca. 1 and $30 \mathrm{mgC}$ when parameters are varied by $\pm 10 \%$ (Table 2 ). Overall, however, lifehistory optimization predicts potentially large differences in maturation size between native and invaded populations. 
The observed difference in estimated maturation age between native and invasive populations is indeed substantial. Controlled laboratory investigations with invasive and native populations (Table 3) show that animals start reproduction at a significant smaller size (co-variance analyses: $P<0.0001$ ) in invasive than in native populations, with a factor of $2-4$ difference in length (Fig. 3a) and more than two orders of magnitude difference in body mass at maturation (Fig. 3b). Specifically, the mean maturation size for native populations (18 \pm $2.05 \mathrm{mgC}, P<0.0001$, Fig. 3b) is close to that predicted by the model, ca. $20 \mathrm{mgC}$ (Fig. 2). In comparison, invasive populations change energy acquisition to reproduction at a much smaller size, and the mean maturation size is just $0.15 \pm 0.02 \mathrm{mgC}(P<0.0001$, Fig. 3b).

Field data on egg production in native and invasive populations similarly showed delayed reproduction at a larger size in native compared to invasive populations, but the difference is not as pronounced as with the laboratory data (Figs. 4). We found that northern and southern populations show similar size-dependencies within native $(P>0.15)$ and invasive $(P>0.58)$ populations. In native populations, the scatter of size-dependent reproduction rates is substantial, indicating high variability between individuals. On the other hand, reproduction rates of invasive field populations show consistently much higher size-specific reproduction rates and hence cluster at the higher end of reproduction rates observed in native areas (Fig. 4a). Egg production rates for both populations increase as a power function of body mass $(y=$ $\left.\mathrm{a} \mathrm{x}^{\mathrm{b}}\right)$, with invasive populations showing faster increase with size $(b=3.69 \pm 0.20)$ than native populations $(1.89 \pm 0.33)$. We further confirm that invasive populations have significantly higher size specific reproduction rates than native populations (co-variance analyses: $P=0.02$ ) and this difference increases with size reaching a factor of 3-4 for the larger individuals (Fig. 4b).

\section{DISCUSSION}


Our hypothesis that invasive populations are selected for high population growth rate $(r)$ and hence should mature at a smaller size and display higher size specific reproduction rates was supported by both laboratory and field data. We show that initiation of energy allocation from growth towards reproduction, and hence maturation, displays a spectacular difference between invasive and native populations in the comb jelly Mnemiopsis leidyi in controlled laboratory experiments. Invasive western Eurasian populations may mature at a body mass two orders of magnitude smaller compared to native populations from America. This difference is predicted by simple fitness optimization arguments. Though it has generally been hypothesized that invasive populations should mature at a smaller size (Parker et al., 2013; Van Kleunen et al., 2015), comparable fecundity data from the native and invasive range remain sparse, especially for animals (Parker et al., 2013). It has been shown that invasive fresh water fish species mature at a smaller size compared to native populations (MacInnis \& Corkum, 2000; Fox et al., 2007; L'avrincikova \& Kovac, 2007). However, the described difference between native and invasive populations is only 10 to $40 \%$ in length (MacInnis \& Corkum, 2000; Fox et al., 2007; L'avrincikova \& Kovac, 2007), while we observe a factor 2 to 4 difference in length at first reproduction, which translates into two orders of magnitude difference in body mass.

The qualitative effect of varying maturation size on $R_{0}$ and $r$ predicts the observed effect and confirms the general expectations (Brommer, 2000; Kiørboe \& Hirst, 2008). The basic trade-off is between early maturation at a small size with consequently low fecundity but high survival chance vs. late maturation at large size and high fecundity but lower chance of surviving to maturation. Because $r$ scales inversely with generation time $\left(r \sim \ln \left(R_{0}\right) / T\right.$, where $T$ is the generation time) and, hence, with maturation age, maximizing $r$ leads to lower optimal maturation size than maximizing $R_{0}$. Thus, simpler arguments lead to a similar qualitative prediction as the more elaborate population model presented here. 
An alternative explanation for the much smaller maturation size in invaded populations is higher juvenile mortality in invaded compared to native populations. This would similarly select for earlier maturation (Stearns, 1992; Taylor \& Gabriel, 1992). However, invasive populations may rather escape their native predators at a biogeographical scale (Colautti et al., 2004), and there is generally no indication that predation pressure should be higher in invaded compared to native habitats (Wolfe, 2002).

The more specific model developed here for M. leidyi predicts that the fitness curve for $R_{0}$ is rather flat (Fig. 2). This allows for a large variation in reproductive traits in the native population. The empirical field data show that size at first reproduction and, in particular, size-specific egg production is more variable in native than in invasive populations, with the reproductive performance of native population ranging between as good as invaded populations to much worse, irrespective of sampling time and regional coverage. This larger variability is consistent with a flat fitness curve for native populations and allows for a large genotypic variation, which, in turn is substrate for selection of different phenotypes during invasion. The large scatter of reproduction rates in native American populations thus suggests that higher reproductive output in invaded habitats is due to selection from available genetic variation in the founder populations (Barrett \& Schluter, 2008). This is corroborated by the lower genetic diversity in invasive western Eurasian populations compared to native parental populations of M. leidyi (Reusch et al., 2010). Similarly, high genetic diversity in the source population has been shown to be important for colonization success in plants (Crawford \& Whitney, 2010).

The high absolute value of $R_{0}$ attained by our model is unrealistic and is likely due to very high egg mortality in the field, which has not been considered in the model. For copepods, it has been shown that freely spawned eggs can have orders of magnitude higher mortality than the newly hatched larvae and later stages and with much less than $1 \%$ surviving to hatching 
despite short ( 1 day) hatching times (Kiørboe et al., 1988; Peterson \& Kimmerer, 1994). Something similar may be the case for M. leidyi. However, high egg mortality does not change the shape of the dependency of $R_{0}$ on maturation size and, hence, our conclusion.

Parker et al. (2013) showed that observed differences in fecundity between native and invasive populations were mainly documented for plants and that none of the included animal species displayed substantial fecundity differences. Such lack of evidence for animals may be caused by differences between invasive sub-populations that can differ in dispersal related life-history traits, depending on time since establishment (Van Kleunen et al., 2015; Chuang \& Peterson, 2016). Hence, pioneer sub-populations at the forefront display higher dispersal and fecundity traits compared to the invasive core population and these traits fade as population density increase (Phillips et al., 2010; Gutowsky \& Fox, 2012; Lindström et al., 2013; Huang et al., 2015). In our case we see that irrespectively of time since invasion, 35 and 10 years or ca. 350 and ca. 100 generations after establishment in southern and northern Europe, respectively, populations in the invasive realm remain selected for opportunistic traits. The dynamic nature of marine environments along with multiple re-invasions (Ghabooli et al., 2010; Reusch et al., 2010) and a constantly moving range expansion front in northern Europe (Hosia \& Falkenhaug, 2015) may explain sustained invasive traits in western Eurasian populations of $M$. leidyi, despite the long time since the species was first recorded. Since connectivity is much higher in the marine realm compared to near shore, terrestrial or fresh-water systems (Kinlan \& Gaines, 2003), density dependence might be temporarily and spatially offset. This might further explain the observed large scatter in reproductive tactics in the native habitat, which makes the American population a potent invasion source.

To our knowledge, this is the first study of fecundity trait differences in a holoplanktonic self-fertilizing marine invasive species. We see that, irrespectively of time since invasion, a spectacular difference in size at maturation persists in invasive populations of the comb jelly 
M. leidyi. We argue that multiple successful invasions of this species, now reaching a global distribution (Costello et al., 2012), are caused partly by the large variation in reproductive traits in the source population. Such large variation constitutes a substrate for selection and an important characteristic of a successful invasive species.

\section{Acknowledgements}

This work received funding from the Danish Council for Independent Research and the European Commission - Marie-Curie Program with the DFF-MOBILEX mobility grant number: DFF-1325-00102B (CJ). The Centre for Ocean Life is supported by the Villum Foundation. We thank J. Javidpour for providing larvae to establish the Caspian M. leidyi cultures. No competing financial interests are associated with this submission.

Author contributions: Conceived and designed the experiments: CJ, TK. Performed the experiments: CJ. Analyzed the data: CJ, LM, TK. Contributed reagents/materials/analysis tools: CJ, LM. Wrote the paper: CJ, TK, LM.

Supporting information: Additional Supporting Information can be found in the online version of this article:

Figure S1. Individual life-history processes of the comb jelly M. leidyi

Figure S2. Regression between oral-aboral (OA, mm) and total (TL, mm) length of M. leidyi

Data availability: All data are deposited on Dryad (https://doi.org/10.5061/dryad.v49vd).

\section{References}

Andersen KH, Beyer, JE (2006) Asymptotic size determines species abundance in the marine size spectrum. American Naturalist, 168, 54-61.

Baker HG (1974) The evolution of weeds. Annual Review of Ecology and Systematics, 5, 124.

Baker LD, Reeve, MR (1974) Laboratory culture of the lobate ctenophore Mnemiopsis mccradyi with notes on feeding and fecundity. Marine Biology, 26, 57-62. 
Barrett RDH, Schluter, D (2008) Adaptation from standing genetic variation. Trends in Ecology \& Evolution, 23, 38-44.

Berggreen U, Hansen, B, Kiørboe, T (1988) Food size spectra, ingestion and growth of the copepod Acartia tonsa during development - implications for determination of copepod production. Marine Biology, 99, 341-352.

Brommer JE (2000) The evolution of fitness in life-history theory. Biological Reviews of the Cambridge Philosophical Society, 75, 377-404.

Butchart SH, Walpole, M, Collen, B, Van Strien, A, Scharlemann, JP et al. (2010) Global biodiversity: Indicators of recent declines. Science, 328, 1164-8.

Chuang A, Peterson, CR (2016) Expanding population edges: Theories, traits and trade-offs. Global Change Biology, 22, 494-512.

Colautti RI, Ricciardi, A, Grigorovich, IA, Macisaac, HJ (2004) Is invasion success explained by the enemy release hypothesis? Ecology Letters, 7, 721-733.

Costello JH, Bayha, KM, Mianzan, HW, Shiganova, TA, Purcell, JE (2012) Transitions of Mnemiopsis leidyi (Ctenophora: Lobata) from a native to an exotic species: A review. Hydrobiologia, 690, 21-46.

Crawford KM, Whitney, KD (2010) Population genetic diversity influences colonization success. Molecular Ecology, 19, 1253-1263.

Dam HG (2013) Evolutionary adaptation of marine zooplankton to global change. Annual Review of Marine Science, 5, 349-370.

Davis HG (2005) r-Selected traits in an invasive population. Evolutionary Ecology, 19, $255-$ 274.

Day T, Taylor, PD (1997) Von Bertalanffy's growth equation should not be used to model age and size at maturity. American Naturalist, 149, 381-393.

Finenko GA, Kideys, AE, Anninsky, BE, Shiganova, TA, Roohi, A et al. (2006) Invasive ctenophore Mnemiopsis leidyi in the Caspian Sea: Feeding, respiration, reproduction and predatory impact on the zooplankton community. Marine Ecology Progress Series, 314, 171-185.

Fox MG, Vila-Gispert, A, Copp, GH (2007) Life-history traits of introduced Iberian pumpkinseed Lepomis gibbosus relative to native populations. Can differences explain colonization success? Journal of Fish Biology, 71, 56-69.

Fox MG, Copp, GH (2014) Old world versus new world: Life-history alterations in a successful invader introduced across Europe. Oecologia, 174, 435-446.

Gallardo B, Clavero, M, Sanchez, MI, Vila, M (2016) Global ecological impacts of invasive species in aquatic ecosystems. Global Change Biology, 22, 151-163.

Ghabooli S, Shiganova, TA, Zhan, A, Cristescu, ME, Eghtesadi-Araghi, P et al. (2010) Multiple introductions and invasion pathways for the invasive ctenophore Mnemiopsis leidyi in Eurasia. Biological Invasions, 13, 679-690.

Gutowsky LFG, Fox, MG (2012) Intra-population variability of life-history traits and growth during range expansion of the invasive round goby, Neogobius melanostomus. Fisheries Management and Ecology, 19, 78-88.

Hansen PJ, Bjørnsen, PK, Hansen, BW (1997) Zooplankton grazing and growth: Scaling within the 2-2,000 $\mu \mathrm{m}$ body size range. Limnology and Oceanography, 42, 687-704.

Hosia A, Falkenhaug, T (2015) Invasive ctenophore Mnemiopsis leidyi in Norway. Marine Biodiversity Records, 8, 1-9.

Huang F, Peng, S, Chen, B, Liao, H, Huang, Q et al. (2015) Rapid evolution of dispersalrelated traits during range expansion of an invasive vine Mikania micrantha. Oikos, 124, 1023-1030. 
Jaspers C, Carstensen, J (2009) Effect of acid Lugol solution as preservative on two representative chitineous and gelatinous zooplankton groups. Limnology and Oceanography: Methods, 7, 430-435.

Jaspers C, Møller, LF, Kiørboe, T (2011) Salinity gradient of the Baltic Sea limits the reproduction and population expansion of the newly invaded comb jelly Mnemiopsis leidyi. PLoS One, 6, e24065-e24065.

Jaspers C, Costello, JH, Colin, SP (2015a) Carbon content of Mnemiopsis leidyi eggs and specific egg production rates in northern Europe. Journal of Plankton Research, 37, $11-15$.

Jaspers C, Møller, EF, Kiørboe, T (2015b) Reproduction rates under variable food conditions and starvation in Mnemiopsis leidyi: Significance for the invasion success of a ctenophore. Journal of Plankton Research, 37, 1011-1018.

Kideys AE (2002) Fall and rise of the Black Sea ecosystem. Science, 297, 1482-1484.

Kinlan BP, Gaines, SD (2003) Propagule dispersal in marine and terrestrial environments: A community perspective. Ecology, 84, 2007-2020.

Kiørboe T, Mohlenberg, F, Tiselius, P (1988) Propagation of planktonic copepods production and mortality of eggs. Hydrobiologia, 167, 219-225.

Kiørboe T, Hirst, AG (2008) Optimal development time in pelagic copepods. Marine Ecology Progress Series, 367, 15-22.

Kremer P (1976a) Population dynamics and ecological energetics of a pulsed zooplankton predator, the ctenophore Mnemiopsis leidyi. In M. Wiley (ed) Estuarine Processes. Vol. 1. Academic Press, New York, USA, pp. 197-215.

Kremer P (1976b) The ecology of the ctenophore Mnemiopsis leidyi in Narragansett Bay. $\mathrm{PhD}$ Thesis. University of Rhode Island, University of Rhode Island, RI, USA, (University Microfilms International, London, UK), pp. 1-311.

Kremer P, Nixon, S (1976) Distribution and abundance of ctenophore, Mnemiopsis leidyi in Narragansett Bay. Estuarine and Coastal Marine Science, 4, 627-639.

L'avrincikova M, Kovac, V (2007) Invasive round goby Neogobius melanostomus from the Danube mature at small size. Journal of Applied Ichthyology, 23, 276-278.

Laugier GJM, Le Moguedec, G, Tayeh, A, Loiseau, A, Osawa, N et al. (2013) Increase in male reproductive success and female reproductive investment in invasive populations of the harlequin ladybird Harmonia axyridis. PLoS One, 8.

Lee CE, Gelembiuk, GW (2008) Evolutionary origins of invasive populations. Evolutionary Applications, 1, 427-448.

Lindström T, Brown, GP, Sisson, SA, Phillips, BL, Shine, R (2013) Rapid shifts in dispersal behavior on an expanding range edge. Proceedings of the National Academy of Sciences of the United States of America, 110, 13452-13456.

Lowe S, Browne, M, Boudjelas, S, De Poorter, M (2000) 100 of the world's worst invasive alien species: A selection from the Global Invasive Species Database. Vol., Hollands Printing Ltd, Aukland.

MacArthur RH, Wilson, EO (1967) The theory of island biogeography. Vol., Princeton Univ Press, New Jersey.

MacInnis AJ, Corkum, LD (2000) Fecundity and reproductive season of the round goby Neogobius melanostomus in the upper Detroit River. Transactions of the American Fisheries Society, 129, 136-144.

Mack RN, Simberloff, D, Lonsdale, WM, Evans, H, Clout, M et al. (2000) Biotic invasions: Causes, epidemiology, global consequences and control. Ecological Applications, 10, 689-710.

McGurk MD (1986) Natural mortality of marine pelagic fish eggs and larvae - role of spatial patchiness. Marine Ecology Progress Series, 34, 227-242. 
McKnight E, Gracia-Berthou, E, Srean, P, Ruis, M (2017) Global meta-analysis of native and nonindigenous trophic traits in aquatic ecosystems. Global Change Biology, 23, 18611870.

McMahon RF (2002) Evolutionary and physiological adaptations of aquatic invasive animals: r selection versus resistance. Canadian Journal of Fisheries and Aquatic Sciences, 59, $1235-1244$.

Ordonez A (2014) Global meta-analysis of trait consistency of non-native plants between their native and introduced areas. Global Ecology and Biogeography, 23, 264-273.

Parker JD, Torchin, ME, Hufbauer, RA, Lemoine, NP, Alba, C et al. (2013) Do invasive species perform better in their new ranges? Ecology, 94, 985-994.

Peterson WT, Kimmerer, WJ (1994) Processes controlling recruitment of the marine calanoid copepod Temora longicornis in Long Island Sound: Egg production, egg mortality and cohort survival rates. Limnology and Oceanography, 39, 1594-1605.

Phillips BL, Brown, GP, Shine, R (2010) Life-history evolution in range-shifting populations. Ecology, 91, 1617-1627.

Pysek P, Richardson, DM (2007) Traits associated with invasiveness in alien plants: Where do we stand? In W. Nentwig (ed) Biological Invasions. Springer, Berlin, pp. 97-125.

Reusch TBH, Bolte, S, Sparwel, M, Moss, AG, Javidpour, J (2010) Microsatellites reveal origin and genetic diversity of Eurasian invasions by one of the world's most notorious marine invader, Mnemiopsis leidyi (Ctenophora). Molecular Ecology, 19, 2690-9.

Riisgård HU, Bøttiger, L, Madsen, C, Purcell, J (2007) Invasive ctenophore Mnemiopsis leidyi in Limfjorden (Denmark) in late summer 2007 - assessment of abundance and predation effects. Aquatic Invasions, 2, 395-401.

Robinson KL (2012) Climate drives local to global variations of coastal gelatinous zooplankton. PhD Thesis, University of South Alabama, Mobile, AL, USA, pp. 237.

Robinson KL, Graham, WM (2014) Warming of subtropical coastal waters accelerates Mnemiopsis leidyi growth and alters timing of spring ctenophore blooms. Marine Ecology Progress Series, 502, 105-115.

Sargent LW, Lodge, DM (2014) Evolution of invasive traits in non-indigenous species: Increased survival and faster growth in invasive populations of rusty crayfish (Orconectes rusticus). Evolutionary Applications, 7, 949-961.

Seebens H, Blackburn, TM, Dyer, EE, Genovesi, P, Hulme, PE et al. (2017) No saturation in the accumulation of alien species worldwide. Nature Communications, 8, 14435.

Stanlaw KA, Reeve, MR, Walter, MA (1981) Growth, food and vulnerability to damage of the ctenophore Mnemiopsis mccradyi in its early life history stages. Limnology and Oceanography, 26, 224-234.

Stearns SC (1992) The evolution of life histories. $1^{\text {st }}$ edn., Oxford University Press, Oxford, UK.

Sullivan LJ, Gifford, DJ (2004) Diet of the larval ctenophore Mnemiopsis leidyi A. Agassiz (Ctenophora, Lobata). Journal of Plankton Research, 26, 417-431.

Taylor BE, Gabriel, W (1992) To grow or not to grow - optimal resource-allocation for Daphnia. American Naturalist, 139, 248-266.

Tingley R, Vallinoto, M, Sequeira, F, Kearney, MR (2014) Realized niche shift during a global biological invasion. Proceedings of the National Academy of Sciences of the United States of America, 111, 10233-10238.

Tobin PC, Berec, L, Liebhold, AM (2011) Exploiting allee effects for managing biological invasions. Ecology Letters, 14, 615-24.

Van Kleunen M, Dawson, W, Maurel, N (2015) Characteristics of successful alien plants. Molecular Ecology, 24, 1954-1968. 
Walsh JR, Carpenter, SR, Vander Zanden, MJ (2016) Invasive species triggers a massive loss of ecosystem services through a trophic cascade. Proceedings of the National Academy of Sciences of the United States of America, 113, 4081-4085.

West GB, Brown, JH, Enquist, BJ (1997) A general model for the origin of allometric scaling laws in biology. Science, 276, 122-126.

Williamson M, Fitter, A (1996) The varying success of invaders. Ecology, 77, 1661-1666.

Wolfe LM (2002) Why alien invaders succeed: Support for the escape-from-enemy hypothesis. American Naturalist, 160, 705-711. 
Table 1: Life-history trait model parameters.

\begin{tabular}{llll} 
Parameter & Equation & Default value \\
\hline$n \quad$ & allometric scaling of energy acquisition rate & $1,2,4$ & $3 / 4$ \\
$h \quad$ & weight-specific acquisition rate & 1,2 & $0.07 \mathrm{mg}^{1-\mathrm{n}} \mathrm{C} \mathrm{d}^{-1}$ \\
$\Theta \quad$ steepness of energy allocation to reproduction & 3 & 2.035 \\
$m_{0} \quad$ weight of an egg & $2,6,8-10$ & $0.22 \times 10^{-3} \mathrm{mgC}$ \\
$m^{*} \quad$ mean maturation size & $1-3$ & $0.155 \mathrm{mgC}$ \\
$m_{\infty} \quad$ final individual size & 9,10 & $100 \mathrm{mgC}^{-3}$ \\
$\mu_{0} \quad$ Constant in size-mortality relationship & 4 & $8.12 \times 10^{-2} \mathrm{~d}^{-1}$ \\
$\mu_{1} \quad$ exponent in size-mortality relationship & 4 & $9.08 \times 10^{-3} \mathrm{mg}^{1-\mathrm{n}} \mathrm{C} \mathrm{d}^{-1}$
\end{tabular}


Table 2: Mnemiopsis leidyi life-history model sensitivity analyses for maturation size ( $\mathrm{m}^{*}$, $\mathrm{mgC}$ ), where optimum $R_{0}$ is reached with parameters varied by $10 \%$ around the default values (see Table 1).

\begin{tabular}{lcc} 
Parameter & $\mathbf{+ 1 0 \%}$ & $\mathbf{- 1 0 \%}$ \\
\hline$h \pm 10 \%$ & 26.6 & 12.7 \\
$n \pm 10 \%$ & 30.1 & 6.8 \\
$\mu_{0} \pm 10 \%$ & 1.3 & 28.1 \\
$\mu_{1} \pm 10 \%$ & 11.6 & 24.7
\end{tabular}




\section{Table 3: Literature review of available $M$. leidyi egg production rates in native (USA)}

and invaded (Europe, EUR) habitats covering laboratory (lab) and field investigations, with total number of experiments/studies (study), the number of egg production measurements per study $(n)$ and experimental details such as temperature (Temp. \pm SD), incubation volume, salinity range and number of animals per treatment (Ind.); n.a. = no data.

\begin{tabular}{|c|c|c|c|c|c|c|c|c|c|}
\hline Study & Region & Population & Location & $\begin{array}{l}\text { Temp. } \\
\left({ }^{\circ} \mathrm{C}\right)\end{array}$ & $\begin{array}{l}\text { Volume } \\
\text { (L) }\end{array}$ & Salinity & Ind. & $n$ & References \\
\hline 1 & NE USA & Native & field & $8-22.5^{\S}$ & n.a. & n.a. & 1 & 254 & $\begin{array}{l}\text { (Kremer, 1976b; } \\
\text { Kremer, 1976a)** }\end{array}$ \\
\hline 2 & SE USA & Native & field & $\begin{array}{l}21,26, \\
31^{\S \S}\end{array}$ & 2 & n.a. & 1 & 57 & $\begin{array}{l}\text { (Baker \& Reeve, } \\
\text { 1974)* }\end{array}$ \\
\hline 3 & $\begin{array}{l}\text { N EUR, } \\
\text { Kattegat }\end{array}$ & invasive & field & $12.5 \pm 1.3$ & 1 to 13.5 & $21-29$ & 1 & 52 & $\begin{array}{l}\text { (Jaspers et al., } \\
\text { 2011) }\end{array}$ \\
\hline 4 & $\begin{array}{l}\text { N EUR, } \\
\text { Baltic Sea }\end{array}$ & invasive & field & $12.5 \pm 1.3$ & 1 to 13.5 & $7.8 \pm 0.3^{a}$ & 1 & 47 & $\begin{array}{l}\text { (Jaspers et al., } \\
\text { 2011) }\end{array}$ \\
\hline 5 & $\begin{array}{l}\text { N EUR, } \\
\text { Skagerrak }\end{array}$ & invasive & field & 16.5 & 4 or 7.5 & 22.5 & 1 & 97 & this study \\
\hline 6 & S EUR & invasive & field & 22 & 2 & n.a. & 1 & 25 & $\begin{array}{l}\text { (Finenko et al., } \\
\text { 2006)* }\end{array}$ \\
\hline 7 & $\begin{array}{l}\text { SE USA, } \\
\text { Gulf of } \\
\text { Mexico }\end{array}$ & Native & $\begin{array}{l}\text { lab, cohort } \\
\text { analysis }\end{array}$ & $16-20^{\S}$ & 2 & 20 & 2 & 60 & (Robinson, 2012) \\
\hline 8 & $\begin{array}{l}\text { SE USA, } \\
\text { FL, Miami }\end{array}$ & Native & $\begin{array}{l}\text { Lab, cohort } \\
\text { analysis }\end{array}$ & 21 & 19 & n.a. & 1 & 84 & $\begin{array}{l}\text { (Baker \& Reeve, } \\
\text { 1974)* }\end{array}$ \\
\hline 9 & N EUR & invasive & $\begin{array}{l}\text { lab, cohort } \\
\text { analysis }\end{array}$ & $19.5 \pm 0.5$ & 7.5 & 33 & 10 & $270 \dagger$ & this study \\
\hline 10 & N EUR & invasive & lab & $19 \pm 0.4$ & 7.5 & $25 \& 33$ & 1 & 11 & $\begin{array}{l}\text { (Jaspers et al., } \\
\text { 2011) }\end{array}$ \\
\hline 11 & $\begin{array}{l}\text { N \& SE } \\
\text { EUR }\end{array}$ & invasive & $\begin{array}{l}\text { lab, common } \\
\text { garden }\end{array}$ & $16.5 \pm 0.5$ & 1 & 33 & 1 & 19 & this study \\
\hline 12 & N EUR & invasive & $1 a b^{* * *}$ & $19 \pm 0.5$ & 20 & 33 & 1 & 23 & $\begin{array}{l}\text { (Jaspers et al., } \\
2015 \mathrm{~b})\end{array}$ \\
\hline 13 & SE EUR & invasive & lab & 17 & 7.5 & 33 & 1 & 11 & this study \\
\hline \multicolumn{10}{|c|}{ 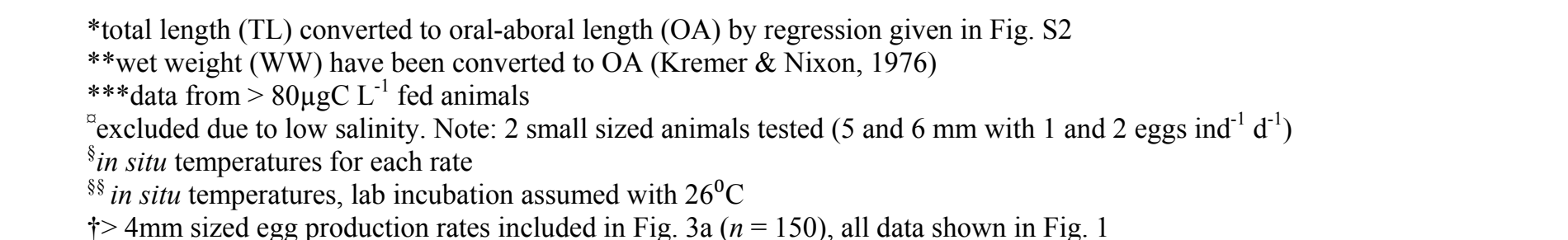 } \\
\hline
\end{tabular}




\section{Figure captions}

Figure 1 Growth and reproduction rates of a Mnemiopsis leidyi laboratory cohort of invasive origin. Body mass $\left(\mathrm{mgC}, \pm \mathrm{SD}\right.$, circles) and specific egg production rates $\left(\mathrm{d}^{-1} \pm \mathrm{SD}\right.$, grey squares) are displayed and initially high specific growth rates of $0.4 \mathrm{~d}^{-1}\left(R^{2}=0.93, P<\right.$ 0.0001 ) for $<14$ day larvae (black/white circle) are reduced to $1 / 5^{\text {th }}\left(0.08 \mathrm{~d}^{-1}, R^{2}=0.69, P<\right.$ 0.0001 , black circle) after start of metamorphosis (dashed vertical line).

Figure 2 Mnemiopsis leidyi life-history model predictions with default parameters (Table 1) for lifetime reproductive success ( $R_{0}$ (dimensionless), left, red line) and population growth rate $\left(r\left(\mathrm{~d}^{-1}\right)\right.$, right, blue line) as a function of maturation size $(\mathrm{mgC})$. The maturation size $\left(\mathrm{m}^{*}\right)$ for highest value of $R_{0}$ is $20.5 \mathrm{mgC}$ (red dot).

Figure 3 Laboratory reproduction and growth data for Mnemiopsis leidyi from invaded (western Eurasia, red circle) and native (USA, blue squares) populations. (a) Egg production as function of size (oral-aboral, mm; total: $n=478,>4 \mathrm{~mm}: n=358$ ), temperature corrected to $19.5^{\circ} \mathrm{C}$ (see Table 1) including northern (filled symbols) and southern (open symbols) subpopulations of native (squared) and invasive (circle) origin with invasive laboratory animals starting reproduction at significantly smaller size than native $M$. leidyi $\left(F_{1,355}=258.4, P<\right.$ 0.0001 co-variance analyses, intercepts are significantly different). (b) Fraction of surplus energy allocated to reproduction (SPE $=$ reproduction $/($ growth + reproduction) ) as a function of body mass $(\mathrm{mgC})$ for laboratory cohort populations. The dotted lines are fits of equation 3 to the data, and the estimated maturation size is $0.15 \pm 0.02 \mathrm{mgC}$ for invasive (red circle, $n=$ $22, t=8.06, P<0.0001$ ) and $18 \pm 2.05 \mathrm{mgC}$ for native (blue squares, $n=84, t=8.82, P<$ $0.0001)$ M. leidyi, respectively.

Figure 4 Reproduction rates for field populations of Mnemiopsis leidyi from native (blue) and invasive (red) populations. (a) Daily egg production as a function of size in northern (filled) and southern (open symbols) populations from native (blue square) and invasive (red circle) habitats. The egg production rates do not differ between northern and southern populations for neither native $\left(F_{1,170}=2.10, P=0.15\right)$ nor invasive $\left(F_{1,307}=0.316, P=0.58\right)$ populations, but are significantly different between native and invasive populations $(P=$ $0.02)$. (b) Average reproduction rates $( \pm \mathrm{SD}$ ) as a function of size in native (blue) and invaded (red) populations for $1 \mathrm{~cm}$ size bins. Egg production rates increase as a power function of body mass, with invaded population showing faster increase with size (power $b=$ $3.69 \pm 0.20)$ than native populations $(1.89 \pm 0.33)$, and invasive populations have significantly higher egg production rates than native populations (co-variance analyses of all available field data: $F_{1,481}=5.313, P=0.02, n=485$, Table 1$)$. 
Fig. 1

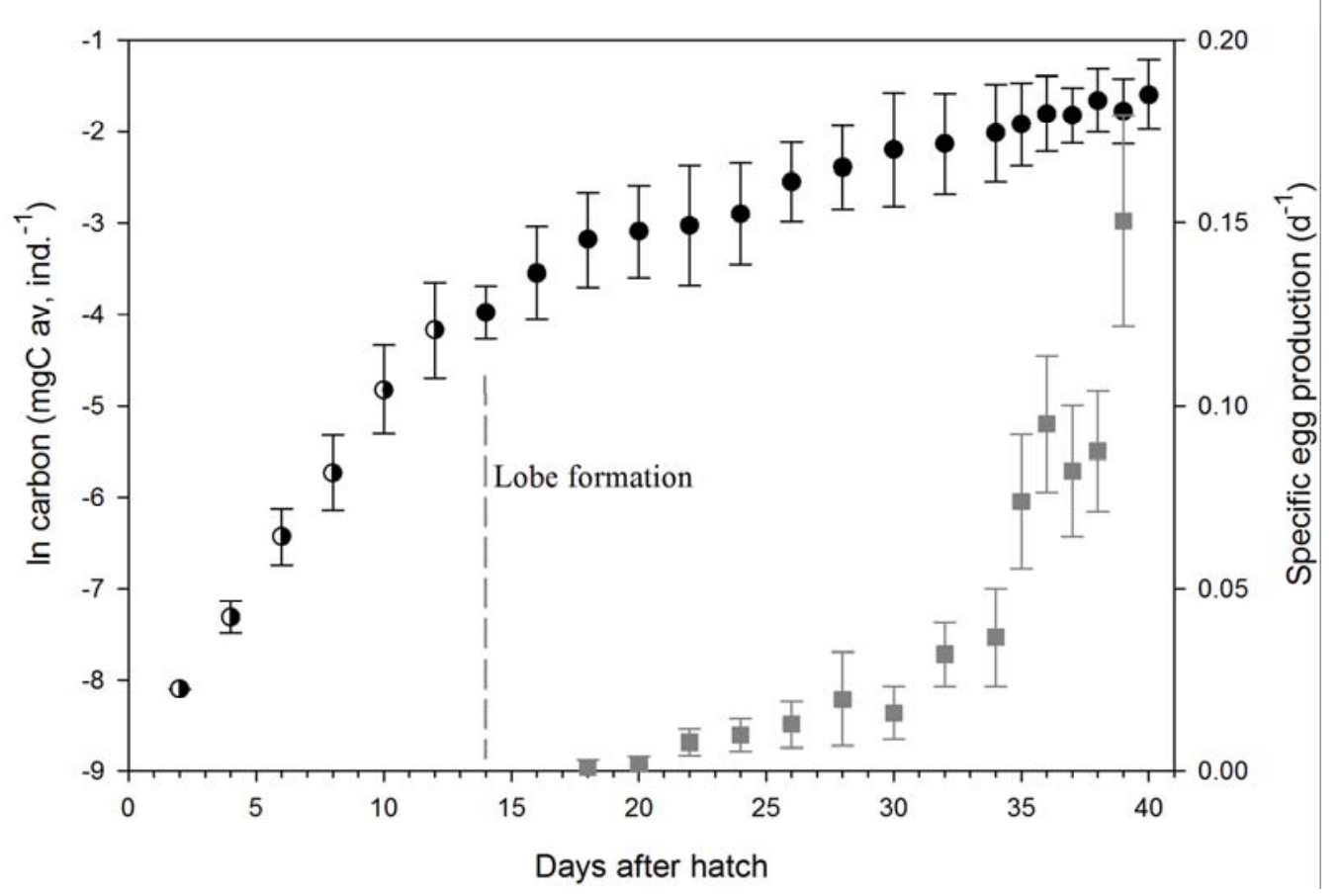


Fig. 2

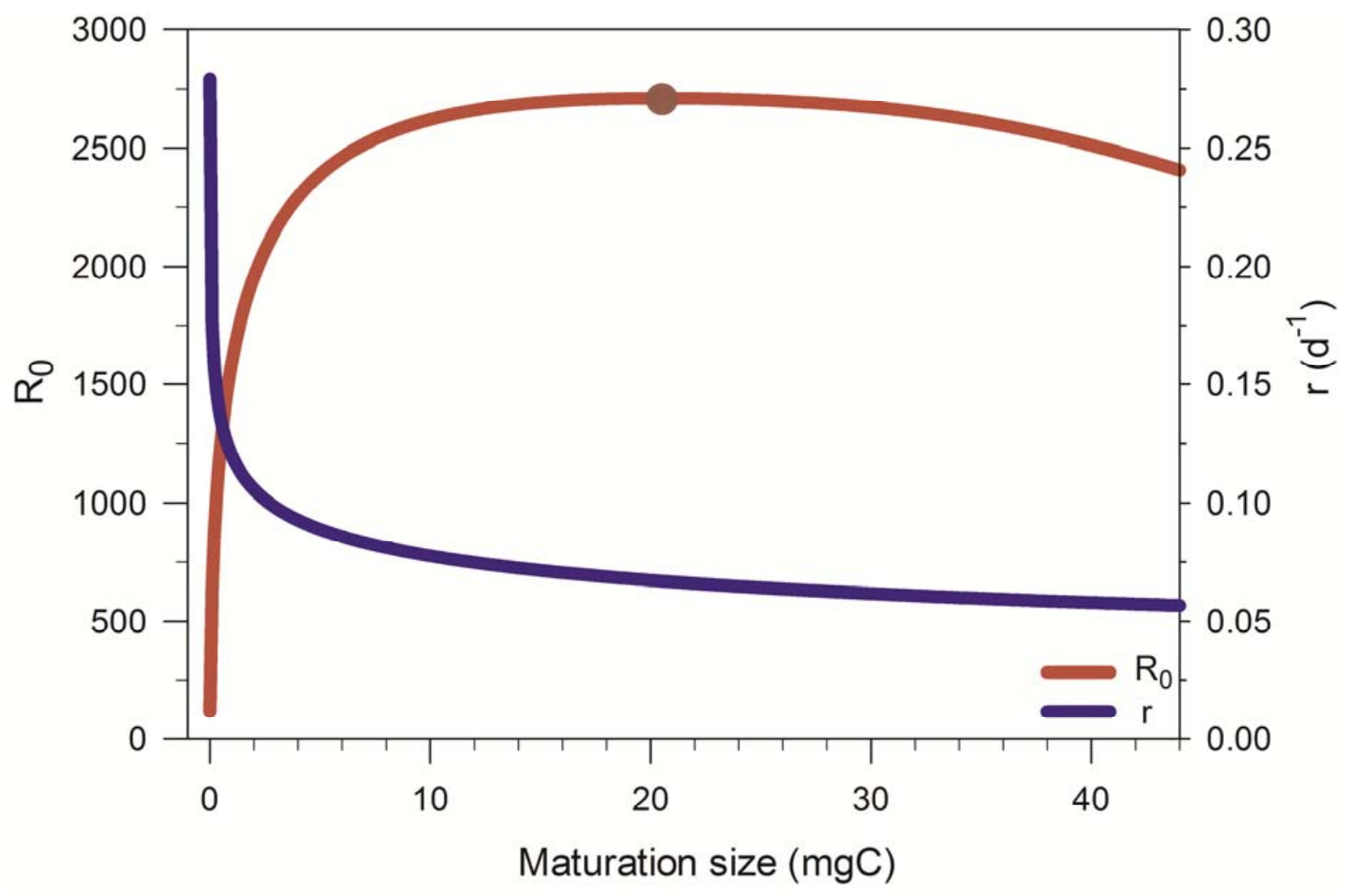


Fig. 3
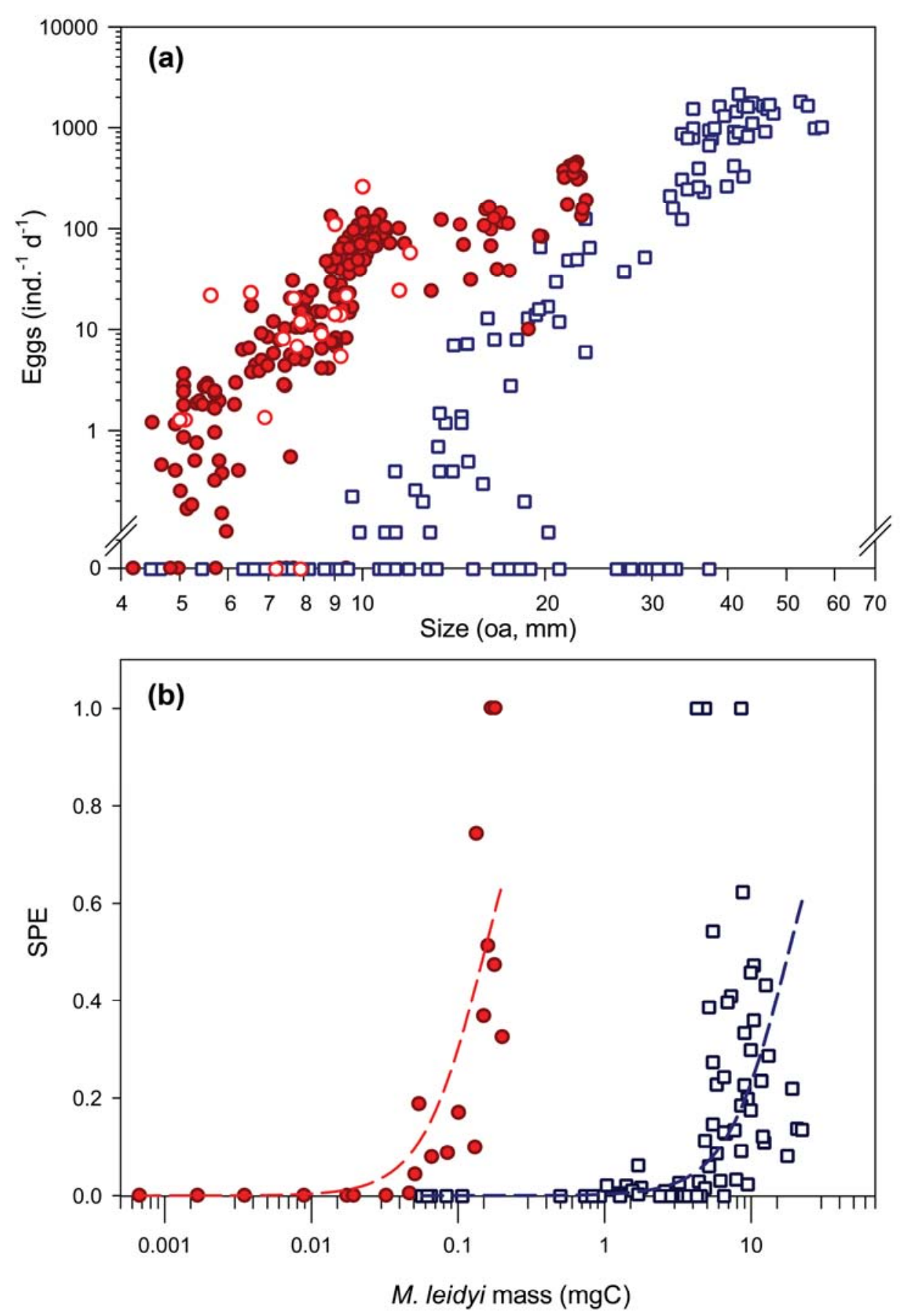
Fig. 4
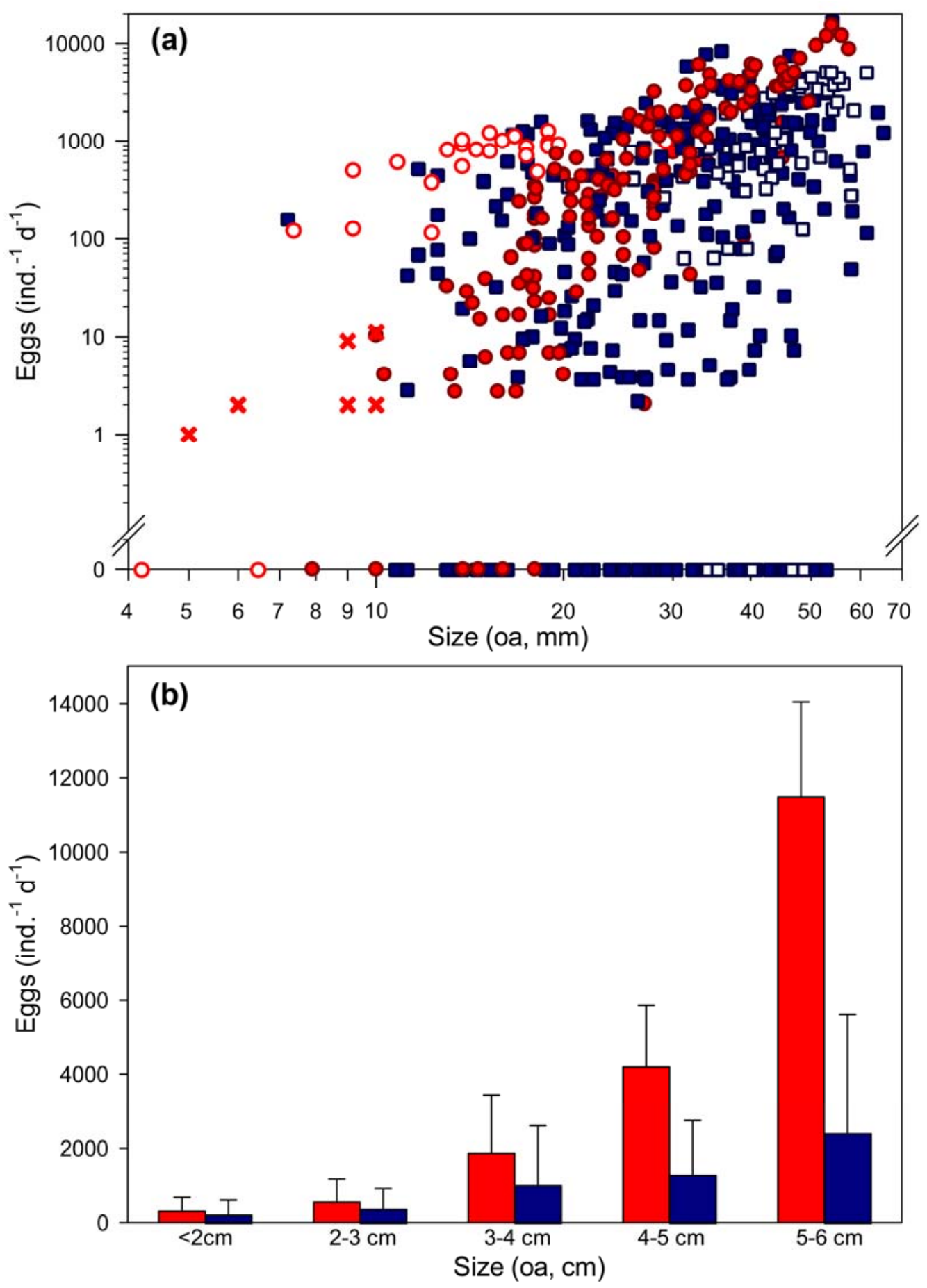